\title{
Changes in cerebral artery blood flow velocity after intermittent cerebrospinal fluid drainage
}

\author{
S T Kempley, H R Gamsu
}

\begin{abstract}
Doppler ultrasound was used to measure blood flow velocity in the anterior cerebral artery of six premature infants with posthaemorrhagic hydrocephalus, before and after intermittent cerebrospinal fluid (CSF) drainage, on 23 occasions. There was a significant increase in mean blood flow velocity after the drainage procedures $(+5.6 \mathrm{~cm} / \mathrm{s}, 95 \%$ confidence interval +2.9 to $+8 \cdot 3 \mathrm{~cm} / \mathrm{s}$ ), which was accompanied by a decrease in velocity waveform pulsatility. CSF pressure also fell significantly. In patients with posthaemorrhagic hydrocephalus, intermittent CSF drainage was associated with acute changes in cerebral haemodynamics.
\end{abstract}

(Arch Dis Child 1993; 69: 74-76)

There is still uncertainty regarding the optimum timing and frequency of intermittent cerebrospinal fluid (CSF) drainage in the management of posthaemorrhagic hydrocephalus. Although the aim of such treatment is to prevent further cerebral damage, it can lead to the introduction of infection, direct ventricular puncture may result in porencephalic cyst formation, and there can be further intraventricular haemorrhage. ${ }^{1}$ A large multicentre trial showed only limited benefit for frequent early drainage performed on the basis of ventricular size when compared with a more conservative regimen. ${ }^{2}$

It is possible, however, that the most important benefit of CSF drainage is the avoidance of compromise of the cerebral circulation resulting from raised intracranial pressure, rather than to prevent anatomical distortion. If this were the case, it would be expected that cerebral blood flow would increase after the procedure.

We have therefore used Doppler ultrasound to measure anterior cerebral artery blood flow velocity, before and after intermittent CSF drainage, in order to determine whether this procedure is associated with any changes in cerebral haemodynamics.

\section{Patients and methods}

Six infants were studied who had posthaemorrhagic hydrocephalus requiring repeated intermittent CSF drainage. Their birth weights, gestations, and other characteristics are shown in table 1. Periventricular haemorrhage was apparent on scans performed at less than 4 hours of age in cases 3 and 5 ; in the remainder the haemorrhage occurred between 2 and 5 days of age. Haemorrhage was graded on the four point scale of Papille et al. ${ }^{3}$

For cases 1-5 the drainage of CSF was performed on clinical grounds, which included the neurological status of the baby, the tension of the fontanelle, the rate of growth of the head circumference, and the appearance of the ventricles on ultrasound. For case 6 only, CSF drainage was performed whenever the ventricular index was more than $4 \mathrm{~mm}$ above the 97 th centile for gestation. Punctures were performed via the lumbar route in cases 2,4 , and 6 , and by direct ventricular puncture in cases 1,3 , and 5 . Case 1 had a ventricular catheter with a subcutaneous reservoir inserted at 36 days of age. Full aseptic precautions were observed during all procedures.

Blood pressures were measured using an oscillometric method (EME Medical) before and after the procedure in five infants. CSF pressure was measured manometrically in four infants, and the measurements subsequently converted into $\mathrm{mm} \mathrm{Hg}$.

Doppler ultrasound measurements were obtained using a duplex imaging and pulsed wave Doppler system (Sonos 100, HewlettPackard). A mechanical sector transducer with a $7.5 \mathrm{MHz}$ imaging frequency and a $5.0 \mathrm{MHz}$ Doppler frequency was used. Measurements were obtained from the ascending portion of the anterior cerebral artery, between the origin
Children Nationwide Neonatal Centre, King's College Hospital, London $S$ T Kempley H R Gamsu

Correspondence to: Dr S T Kempley, Department of Paediatrics, Royal London London E1 1BB.

Accepted 10 February 1993
Table 1 Characteristics of the infants studied

\begin{tabular}{|c|c|c|c|c|c|c|c|}
\hline $\begin{array}{l}\text { Case } \\
\text { No }\end{array}$ & Sex & $\begin{array}{l}\text { Birth } \\
\text { weight } \\
\text { (g) }\end{array}$ & $\begin{array}{l}\text { Gestation } \\
\text { (weeks) }\end{array}$ & $\begin{array}{l}\text { Grade of } \\
\text { periventricular } \\
\text { haemorrhage } \\
(L / R)\end{array}$ & $\begin{array}{l}\text { Other main } \\
\text { diagnoses }\end{array}$ & $\begin{array}{l}\text { Age at which } \\
\text { procedures } \\
\text { measured } \\
\text { (days) }\end{array}$ & Outcome \\
\hline 1 & $\mathbf{M}$ & 1284 & 28 & $3 / 3$ & HMD & $15-49$ & $\begin{array}{l}\text { Ventriculoperitoneal } \\
\text { shunt, survived }\end{array}$ \\
\hline $\begin{array}{l}2 \\
3 \\
4 \\
5\end{array}$ & $\begin{array}{l}\mathbf{F} \\
\mathbf{M} \\
\mathbf{M} \\
\mathbf{F}\end{array}$ & $\begin{array}{r}736 \\
1650 \\
824 \\
760\end{array}$ & $\begin{array}{l}28 \\
31 \\
25 \\
29\end{array}$ & $\begin{array}{l}3 / 4 \\
0 / 4 \\
3 / 4 \\
4 / 3\end{array}$ & $\begin{array}{l}\text { IUGR, HMD, PIE } \\
\text { Dystrophia myotonica } \\
\text { PIE, pneumothorax } \\
\text { IUGR, HMD }\end{array}$ & $\begin{array}{l}11 \\
4-10 \\
10-13 \\
19-22\end{array}$ & $\begin{array}{l}\text { No resolution, died } \\
\text { No resolution, died } \\
\text { No resolution, died } \\
\text { Candida ventriculitis, } \\
\text { died }\end{array}$ \\
\hline 6 & $\mathbf{M}$ & 1246 & 28 & $3 / 3$ & HMD & $16-23$ & Resolved, survived \\
\hline
\end{tabular}

$\mathrm{HMD}=$ hyaline membrane disease, $\mathrm{PIE}=$ pulmonary interstitial emphysema, $\mathrm{IUGR}=$ intrauterine growth retardation. Periventricular haemorrhage was graded on a four point scale. 
Table 2 Anterior cerebral artery blood flow velocity and pulsatility index, mean arterial blood pressure, and CSF pressure. The mean baseline value before the procedure, and the mean change which followed it, are shown for each subject

\begin{tabular}{|c|c|c|c|c|c|c|c|c|c|}
\hline \multirow[b]{2}{*}{$\begin{array}{l}\text { Case } \\
\text { No }\end{array}$} & \multirow[b]{2}{*}{$\begin{array}{l}\text { No of } \\
\text { CSF taps } \\
\text { measured }\end{array}$} & \multicolumn{2}{|c|}{ Velocity $(\mathrm{cm} / \mathrm{s})$} & \multicolumn{2}{|c|}{ Pulsatility index } & \multicolumn{2}{|c|}{ Blood pressure $(\mathrm{mm} \mathrm{Hg})$} & \multicolumn{2}{|c|}{ CSF pressure $(m m ~ H g) *$} \\
\hline & & $\begin{array}{l}\text { Mean } \\
\text { baseline }\end{array}$ & $\begin{array}{l}\text { Mean } \\
\text { change }\end{array}$ & $\begin{array}{l}\text { Mean } \\
\text { baseline }\end{array}$ & $\begin{array}{l}\text { Mean } \\
\text { change }\end{array}$ & $\begin{array}{l}\text { Mean } \\
\text { baseline }\end{array}$ & $\begin{array}{l}\text { Mean } \\
\text { change }\end{array}$ & $\begin{array}{l}\text { Mean } \\
\text { baseline }\end{array}$ & $\begin{array}{l}\text { Mean } \\
\text { change }\end{array}$ \\
\hline $\begin{array}{l}1 \\
2 \\
3 \\
4 \\
5 \\
6\end{array}$ & $\begin{array}{r}11 \\
1 \\
3 \\
2 \\
3 \\
3\end{array}$ & $\begin{array}{l}20.1 \\
10.3 \\
13.6 \\
10.3 \\
11.6 \\
14.8\end{array}$ & $\begin{array}{l}+5 \cdot 8 \\
+8.5 \\
+8.2 \\
+5.4 \\
+4.0 \\
+1.7\end{array}$ & $\begin{array}{l}1 \cdot 56 \\
2 \cdot 88 \\
2 \cdot 36 \\
2 \cdot 04 \\
1 \cdot 78 \\
1 \cdot 88\end{array}$ & $\begin{array}{l}-0.36 \\
-1.04 \\
-0.50 \\
-0.67 \\
-0.48 \\
+0.13\end{array}$ & $\begin{array}{l}46 \\
45 \\
45 \\
36 \\
57 \\
-\end{array}$ & $\begin{array}{l}-2.0 \\
-1.0 \\
+0.7 \\
-1.5 \\
+2.0 \\
-\end{array}$ & $\begin{array}{r}9 \\
\overline{11} \\
13 \\
11 \\
-\end{array}$ & $\begin{array}{l}-5.9 \\
- \\
-9.5 \\
-12.0 \\
-9.0 \\
-\end{array}$ \\
\hline \multicolumn{2}{|c|}{$\begin{array}{l}\text { Mean change } \\
\text { (95\% confidence } \\
\text { interval) }\end{array}$} & $(+2.9 \mathrm{tc}$ & $\begin{array}{l}+5 \cdot 6 \\
3 \cdot 3)\end{array}$ & $(-0.08$ & $\begin{array}{r}-0.49 \\
-0.89)\end{array}$ & & $(-2.5$ to +1.7$)$ & $(-4.0$ to & $\begin{array}{l}-9 \cdot 1 \\
13 \cdot 1)\end{array}$ \\
\hline
\end{tabular}

$\star_{1} \mathrm{~mm} \mathrm{Hg}=0 \cdot 133 \mathrm{kPa}$.

of the artery and the lower border of the corpus callosum. The angle of insonation was measured and was always less than $20^{\circ}$. A 3-4 mm range gate was employed and the wall filter was set at its minimum value of $100 \mathrm{~Hz}$. From each set of Doppler waveforms we obtained a measure of blood flow velocity (the time averaged mean of the peak velocity envelope, corrected for the angle of insonation and averaged over at least four cardiac cycles) and a measure of waveform pulsatility (the pulsatility index of Gosling and King ${ }^{4}$ ).

Measurements were performed just before the procedure, then the puncture was performed, thereafter the infant was allowed to settle for 10-15 minutes, and the measurements were then repeated with the infant lying quietly or asleep. Case 1 also had a number of measurements taken between procedures.

Between one and 11 procedures were measured on each infant. For each subject the mean baseline velocity and the mean change in velocity after the procedure were calculated.
Using these six intrasubject means an overall mean change in velocity was calculated, and statistical analysis was performed using Student's paired $t$ test. The same method of analysis was used for pulsatility index, blood pressure, and CSF pressure data.

\section{Results}

After the drainage procedures, anterior cerebral artery blood flow velocity increased by a mean of $5.6 \mathrm{~cm} / \mathrm{s}(t=5.4,5 \mathrm{df}, \mathrm{p}<0.01$; table 2 ), and pulsatility index fell by a mean of 0.49 $(t=3 \cdot 1,5 \mathrm{df}, \mathrm{p}<0.05)$. Blood flow velocity increased after $20 / 23$ procedures and pulsatility index fell after 19/23 procedures. The increase in mean blood flow velocity was lowest in case 6 in whom the mean pulsatility index was higher after the procedures.

There was no significant change in blood pressure after the procedures, but CSF pressure fell significantly by a mean of $9 \cdot 1$ $\mathrm{mm} \mathrm{Hg}(1.2 \mathrm{kPa})(t=7.3,3 \mathrm{df}, \mathrm{p}<0.01)$.

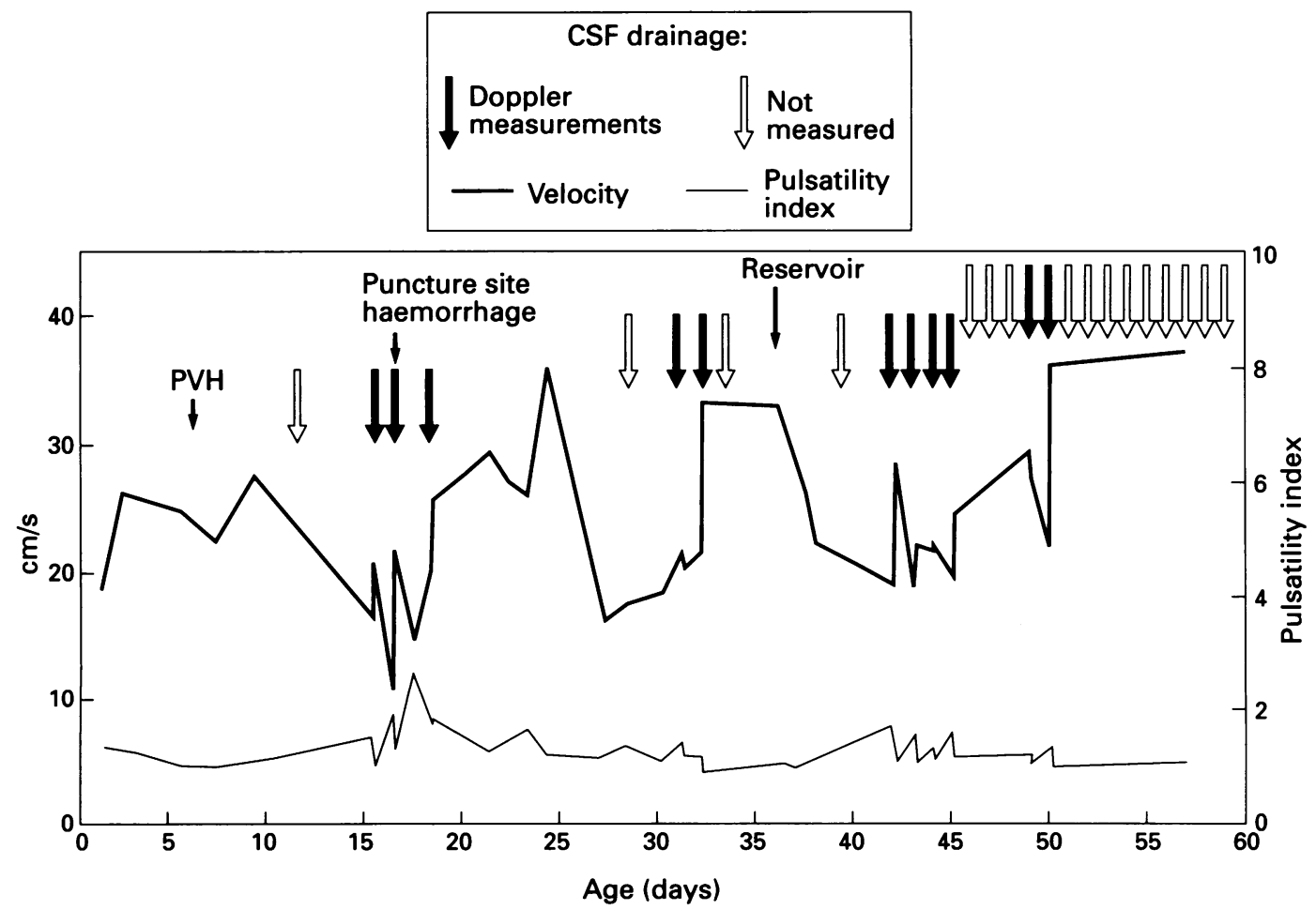

Anterior cerebral artery blood flow velocity and pulsatility index for case 1. The timing of CSF drainage is indicated, with the procedures around which Doppler measurements were performed shown as the solid arrows. After the second procedure there was a small parenchymal haemorrhage at the site of a direct ventricular puncture. $A$ ventricular catheter reservoir was inserted at 36 days of age. PVH=periventricular haemorrhage. 
The figure shows the results from case 1, who was studied in greatest detail. This infant required CSF to be drained via ventricular puncture, as negligible CSF was obtained via the lumbar route. At the time that CSF drainage was commenced, blood flow velocity had fallen to relatively low levels. After the second procedure ultrasound imaging showed a localised parenchymal haemorrhage at the site of the puncture, which later developed into a small parenchymal 'needle track' cyst. Before this procedure blood flow velocity was at its lowest recorded level. Although there were acute changes in blood flow velocity after most of the procedures, there also appeared to be delayed effects, for example a sustained increase in blood flow velocity followed a period of regular CSF drainage, and a sustained reduction in blood flow velocity followed a period when CSF was not drained (such as that which occurred after the insertion of the reservoir). For this infant there was no statistically significant correlation between the change in blood flow velocity and the change in CSF pressure $(r=0.42)$ or the change in cerebral perfusion pressure $(r=0 \cdot 52)$.

Only two of the infants who were studied survived, and neither of these suffer from any major disability, although case 1 has a ventriculoperitoneal shunt. Of the remaining infants, two died of severe respiratory disease (cases 2 and 4), it was impossible to wean the infant with dystrophia myotonica (case 3) from ventilation, and case 5 died with candida ventriculitis.

\section{Discussion}

Intermittent CSF drainage was associated with a significant increase in cerebral artery blood flow velocity and a significant fall in cerebral artery pulsatility index. These changes could be attributed to a number of factors.

It is most likely that the increase in blood flow velocity reflects an increase in cerebral blood flow in response to a reduction in intracranial pressure after CSF drainage. Mean CSF pressure, which is likely to be the same as intracranial pressure, was lower after the procedure in all the infants in whom it was measured. The 'recruitment' effects seen after frequent drainage in infant 1 could also be explained by a gradual decrease in baseline CSF pressure. However, there was no statistically significant association between the size of the increase in blood flow velocity and the magnitude of the change in CSF pressure or cerebral perfusion pressure.

We feel it is unlikely that the changes were caused simply by the disturbance associated with the procedure or the measurements. Each baby was allowed to return to a resting state before the second set of measurements were performed, and mean blood pressure was no higher at this time. We had not previously found any consistent increase when measurements of cerebral artery blood flow velocity were repeated without any therapeutic inter- vention, nor have we seen any change after diagnostic lumbar puncture.

Finally, it is possible that increases in blood flow velocity after CSF drainage do not reflect an increase in the volume of blood flow, but could instead be due to spasm of the major cerebral arteries, with reduced or unchanged cerebral blood flow. This is unlikely for two reasons. Firstly, arterial blood flow velocity has been shown to be closely related to cerebral blood flow in the human newborn, ${ }^{5}$ although we accept that this may not be the case after an invasive procedure such as CSF drainage. Secondly, the reduction in pulsatility index after the procedure suggests a reduction in downstream resistance to flow, ${ }^{6}$ which should have resulted in an increase in cerebral blood flow.

If, as we believe, the changes we have observed are related to changes in cerebral blood flow, then our findings would suggest that intermittent CSF drainage may lead to clinically significant changes in cerebral blood flow at the time of the procedure. It is most likely that the values before the tap are reduced, but a reactive hyperaemia after the procedure cannot be ruled out. It is of note that the haemorrhage along the track of the ventricular puncture in infant 1 occurred when the blood flow velocity before the tap was at its lowest level, with a blood flow velocity after the tap that was not especially raised. This suggests that initial compromise of the cerebral circulation may be more important than rapid changes in blood flow in the aetiology of such haemorrhages. Our experience also suggests that such haemorrhages may be the forerunners of needle track cysts.

A treatment regimen where the number of procedures was limited was found to lead to major variations in CSF pressure and cerebral artery blood flow velocity. We found that the smallest changes in blood flow velocity were seen in the infant who was managed more actively. However, more frequent intervention increases the risk of complications, which may negate the benefits of treatment. ${ }^{2}$ An alternative policy of only draining CSF when cerebral artery blood flow velocity begins to fall might prevent major compromise of the cerebral circulation, and there would be fewer procedures than would be necessary when intervening solely on the basis of ventricular measurements.

1 Moghal NE, Quinn MW, Levene MI, Puntis JWL. Intraventricular haemorrhage after aspiration of ventricular Intraventricular haemorrhage after aspiration

2 Ventriculomegaly Trial Group. Randomised trial of early tapping in neonatal posthaemorrhagic ventricular dilatation. Arch Dis Child 1990; 65: 3-10.

3 Papille LA, Burstein J, Burstein R, Koffler H. Incidence and evolution of subependymal and intraventricular haemorhage: a study of infants with birth weight less than $1500 \mathrm{~g}$. $\mathcal{f}$ Pediatr 1978; 92: 529-34

4 Gosling RG, King DH. Arterial assessment by Doppler-shift ultrasound. Proc $R$ Soc Med 1974; 67(b): 447

5 Greisen G, Johansen K, Ellison PH, Fredriksen PS, Mali J, Frĩs-Hansen $B$. Cerebral blood flow in the newborn infant; comparison of Doppler ultrasound and xenon clearance. fompariatr 1984; 104: 411-8.

6 Skidmore R, Woodcock JP, Wells PNT, Bird D, Baird RN. Physiological interpretation of Doppler-shift waveforms-III. Ultrasound Med Biol 1980; 6: 227-31. 